\title{
Armed military robots: editorial
}

\author{
Jürgen Altmann · Peter Asaro · Noel Sharkey • \\ Robert Sparrow
}

Published online: 20 June 2013

(C) Springer Science+Business Media Dordrecht 2013

The four editors of this special issue met in Sheffield, UK in September 2009, one electronically, after reading each other's papers and discovering that they shared concerns about military plans to develop armed unmanned systems, in particular autonomous ones. Concerns about peace and international stability exist with all such systems, remotely controlled or autonomous. The latter are robot weapons that once launched will select and engage targets without further human intervention. These had been appearing in all of the US roadmaps for all of the US forces since the early 2000s and there had been no international discussion amongst state actors at that time about the ethical, humanitarian and human rights issues that they would create.

\footnotetext{
J. Altmann

Experimentelle Physik III, Technische Universität Dortmund, Dortmund, Germany

e-mail: altmann@e3.physik.tu-dortmund.de

P. Asaro

School of Media Studies, The New School, New York, NY, USA

e-mail: asarop@newschool.edu

P. Asaro

The Center for Internet and Society, Stanford Law School,

Stanford, CA, USA

N. Sharkey $(\bowtie)$

University of Sheffield, Sheffield, UK

e-mail: N.Sharkey@dcs.shef.ac.uk

R. Sparrow

Centre for Human Bioethics, School of Philosophical, Historical and International Studies, Monash University, Clayton,

VIC 3800, Australia

e-mail: robert.sparrow@monash.edu
}

Although we had different as well as shared concerns, we all felt that something needed to be done. This led Altmann, Asaro, Sharkey and Sparrow to found the International Committee for Robot Arms Control (ICRAC) with a very specific mission statement:

Given the rapid pace of development of military robotics and the pressing dangers that these pose to peace and international security and to civilians in war, we call upon the international community to urgently commence a discussion about an arms control regime to reduce the threat posed by these systems.

We propose that this discussion should consider the following:

- Their potential to lower the threshold of armed conflict;

- The prohibition of the development, deployment and use of armed autonomous unmanned systems; machines should not be allowed to make the decision to kill people;

- Limitations on the range and weapons carried by "man in the loop" unmanned systems and on their deployment in postures threatening to other states;

- A ban on arming unmanned systems with nuclear weapons;

- The prohibition of the development, deployment and use of robot space weapons.

The next step in the development of ICRAC came in September 2010 when we had the first ICRAC "summit" in Berlin; we met with a large interdisciplinary group at a workshop on "Arms Control for Robots-Limiting Armed Tele-Operated and Autonomous Systems." The participants discussed many aspects and collectively developed a 
more detailed statement that was endorsed by majority vote and then signed by 21 participants. ${ }^{1}$ Several participants became members of ICRAC.

It was at this meeting that we decided to publish a special issue on Armed Military Robots. There was a need to raise awareness to make these issues more prominent. We specifically targeted the Journal of Ethics and Information Technology because we wanted to reach out to this audience to get them involved with the issues and begin to initiate more active discussions.

Early in the development of our work to raise awareness about robot weapons we were approached by Richard Moyes now managing partner of Article 36, who had been party to achieving an international ban of anti-personnel landmines and cluster munitions. He shared many of our concerns and discussed this with other non-governmental organisations. Then in February 2012, ICRAC was approached by Human Rights Watch to discuss how the issues that we raised about autonomous robot weapons were related to International Humanitarian Law and we began to work together on the issues.

In October the same year, Human Rights Watch met with ICRAC, IVK/Pax Christi, Article 36, The Nobel Women's Initiative and Pugwash in New York and decided to form a coalition to set up a civil society campaign for a new legally binding international treaty to ban the development, production and use of fully autonomous weapons. Then Human Rights Watch released a report "Losing Humanity: the Case Against Killer Robots" in November $2012^{2}$ and three days later the US Department of Defence released a directive for the development of autonomous robot weapons. ${ }^{3}$ At that point the international debate shifted into a new gear and discussion among governmental bodies began in earnest.

On April 23, 2013 the Campaign to stop killer robots was launched formally from the UK Parliament. Now the hard work has begun to create a conceptual space among the political elite to take the issues seriously. On May 29, the UN Human Right Council will receive a report from Professor Christof Heyns, the UN special rapporteur on extrajudicial, summary or arbitrary executions, asking the Human Rights Council to call on all States to declare and implement national moratoria on at least the testing, production, assembly, transfer, acquisition, deployment, and use of lethal autonomous robots until such time as an internationally agreed upon framework on the future of Lethal Autonomous Robots has been established.

This EIT special issue is timely and comes as the international discussions grow louder. The papers here

\footnotetext{
1 http://icrac.net/statements.

2 http://www.hrw.org/reports/2012/11/19/losing-humanity.

${ }^{3}$ http://www.dtic.mil/whs/directives/corres/pdf/300009p.pdf.
}

present a number of different viewpoints that will contribute arguments to the emerging international debate

We are pleased that the contributors to this special issue have taken up the challenge set out in the call for papersto consider the ethical issues raised by the development and deployment of remote piloted, semiautonomous, and autonomous robots for military roles-and that we have been able to publish papers discussing both existing remotely piloted weapon systems and hypothetical future "autonomous weapon systems", as well as some more general reflections about contemporary debates about robotic weaponry.

One of the difficulties involved in writing about existing military robots - and about future developments in the field-is distinguishing fact from science fiction; another is freeing our imagination, and the operation of our moral faculties, from the influence of the representations of these systems in popular culture-in films, books, and video games-where they often appear as science fiction. In his "Militainment and Mechatronics: Occultatio and the Veil of Science Fiction Cool in United States Air Force Advertisements", Nicholas R. Maradin III, uses a close analysis of series of advertisements commissioned by the United States Air Force, which relied on science fiction imagery to represent and valorise air force operations, as an opportunity to reflect more generally on the ways in which science fiction film and video games influence public attitudes towards military technologies. His investigation suggests that science fiction and military technology are now intertwined in a mutually beneficial relationship in which each refers to and influences the other. Existing military technologies form the basis of representations of the future in science fiction; these representations then serve to promote these very same technologies as excitingly "futuristic" and even shape the development of new technologies as scientists seek to bring into existence the weapons and devices that the public now expects the future to contain. As Maradin highlights, these relationships pose important ethical questions regarding the representation of military technologies in popular culture and the military's use of science fiction imagery to promote its operations. We hope that these reflections will serve as a salutary reminder to those thinking about the broader range of ethical issues raised by developments in robotic weaponry that we need to proceed with great care whenever we find ourselves making use of ideas from science fiction or risk mistaking the popular cultural images of these weapons for their reality.

Mark Coeckelbergh is also concerned with questions of representation, and with the significance of video imagery, in his essay "Drones, Information Technology, and Distance: Mapping the Moral Epistemology of Remote Fighting." As Coeckelbergh observes, the development of 
drones, which allow their operators to kill people thousands of kilometres away on the basis of video images they watch in the air-conditioned comfort of control stations in complete safety, might be thought to make killing "too easy." This intuition is by now a familiar one in the debate about the ethics of remote controlled killing. What distinguishes Coeckelbergh's investigation and justifies its publication in this context is the sophistication of his discussion and the depth and breadth of philosophical resources he brings to bear in it. Drawing on arguments from Aristotle, Levinas, and Heidegger, Coeckelbergh develops an account of the "moral distance" that information technology creates between drones their operators and their targets. Yet Coeckelbergh also allows that the operators of drones are themselves still capable of, and involved in, moral reflection about their experiences and that work remains to be done to understand the impact of moral distancing on the choices operators make and its relation to the other social and political dynamics that are shaping drone operations. $\mathrm{He}$ is also admirably clear that the sophisticated surveillance systems mounted on drones also provide their operators with an unprecedented amount of detail about the people they target and about the consequences of their decision to kill. Moral distancing therefore occurs alongside of and simultaneously with a "re-personalisation" of the enemy, which may even make it harder for drone pilots to make the decision to kill than it is for other participants in long-range war fighting. How these two dynamics intersect-and what sorts of interventions might be possible to shape the results so as to reduce the harmful effects of moral distance-remains a topic for further study. In developing a philosophically nuanced account of these issues, Coeckelbergh's paper lays down crucial foundations for future work in this area.

The essays by Thomas Hellström and Ryan Tonkens address issues that would arise should future progress in engineering and computer science lead to the creation of "autonomous" weapons.

In "On the Moral Responsibility of Military Robots" Hellstrom argues for a controversial conclusion regarding the assigning of responsibility for deaths caused by the operations of lethal autonomous robots. He introduces the concept of "autonomous power" as a means via which to assess the relative capacities of artificial agents with differing degrees of physical ability, decision-making power, and scope for interaction. Hellstrom then suggests that in the future it will be necessary to divide responsibility for the activities of autonomous weapons between the human beings who operate and develop them and the robots themselves. Indeed, he suggests that it may eventually make sense to say of robots that are capable of learning from their own experience that they should be punished or rewarded for their actions! Perhaps less controversially,
Hellstrom argues that we should begin thinking now about how to regulate the activities of (hypothetical) lethal autonomous robots through a combination of mechanisms including: limiting the activities of robots to specific domains wherein ethical questions do not arise or are more obviously tractable; maintaining a human being in the loop; and, developing ethics-based control systems for robots based on existing principles within the international Law of War. In the course of this discussion he alludes to the possibility that international Laws of War might be amended to include specific requirements on the behaviour of autonomous robots. This latter prospect is, of course, one that we eagerly anticipate.

Ryan Tonkens advocates a more radical solution to the question as to how to regulate the activity of robots in his paper, "Should autonomous robots be pacifists?" by answering the question he poses in his title in the affirmative. Tonkens observes that the project of developing military robots is implicated in the larger question of the ethics of warfare. Not implausibly, he argues that our basic philosophical stance should be against war and that therefore we should be extremely resistant to the idea that it is desirable to build lethal autonomous robots. He further develops a case against programming robots to kill even if we are prepared to believe that war is sometimes justified, on the basis of various contradictions that, he claims, would be involved this project. Thus, he concludes that either autonomous robots should be programmed to be pacifists or that autonomous robots should not be developed at all. While we suspect that many currently writing in the literature about the ethics of military robots will find Tonkens' perspective challenging, his essay makes a strong case that there is indeed a challenge to be met here.

The remaining two papers in this special issue, by Wendell Wallach and Colin Allen, and by Juergen Altmann, take on the issue of how we might act to prevent remotely piloted and/or autonomous weapons from multiplying wars in the future and further increasing the human costs of war.

In "Framing Robot Arms Control" Wendell Wallach and Colin Allen draw upon their previous work, published in their influential book Moral Machines (2009), to argue that the challenges involved in developing artificial moral agents (AMAs) capable of acting ethically in military roles are greater than contemporary advocates appear to allow. However, they are also concerned that autonomous robots with lethal capabilities may be deployed by states that are willing to accept the risk of unethical behaviour for the sake of the military advantages these systems are perceived to offer. Wallach and Allen themselves believe that it would be best if the decision to initiate lethal force were never to be left to autonomous systems. However, they also acknowledge that there are many challenges that would 
arise in any attempt to impose a blanket ban on autonomous systems, especially surrounding the definition of autonomy and the difficulties involved in the verification of the capacities of robotic systems. Given these challenges, they suggest that a first step towards a new international understanding of the status of autonomous weaponry would be for the president of the United States to issue an executive order that "clarifies limits on initiation of lethal activity by the autonomous weapons systems ... that the US will deploy". They offer several alternative formulations of such a declaration, along with an analysis of the advantages and disadvantages of each. While they concede that their proposal is US-centric and may not in itself stop the development of autonomous lethal weaponry, they suggest that if it this example were to be followed by other nations and to succeed in establishing a principle under international humanitarian law that lethal autonomous weapons are illegal, this would avoid the need to try to limit the risks and harms involved in the development of autonomous weaponry through arms control treaties that are likely to be extremely difficult to negotiate.

Juergen Altmann's essay “Arms Control for Armed Uninhabited Vehicles-An Ethical Issue" sets out the case for arms control of remotely piloted armed Uninhabited Vehicles (UVs) as well as (hypothetical) autonomous weapon systems. He surveys the existing, scant, literature and offers a precisely defined and defensible set of terms to facilitate sensible discussion of the various issues involved. His discussion of the reasons for armed UV arms control is noteworthy for its comprehensiveness and its engagement with broader debates about arms control of conventional and nuclear weapons. Similarly, his discussion of the implications of existing international regulations of weaponry for armed UVs is both wide-ranging and detailed and succeeds in identifying a number of significant gaps in the existing system of regulations. Finally, Altmann sets out a number of options for, and makes various recommendations concerning arms control of armed UVs. He argues that a complete ban on new armed UVs might even appeal to the leadership of those nations that currently possess military supremacy in this area were they to take a sufficiently long term view of their interests. However he concedes that it is perhaps unlikely in the short to medium term. Like Wallach and Allen, he also suggests that a new understanding should be introduced into International Humanitarian Law that a human being should always be involved in the decision to release a lethal weapon. However, Altmann is also concerned to regulate remotelycontrolled armed UVs in the event that a more general prohibition on the development of new armed UVs cannot be agreed upon and distinguishes a number of special categories where regulation is especially necessary. Again, he links this discussion to existing arms control treaties in a fashion that we anticipate will be extremely useful for the development of concrete proposals of how to proceed with the task of achieving such prohibitions and regulations.

We hope that the papers in this special issue, both separately and together, might serve as a model of the sort of thinking that will be required if humanity is to meet the challenge posed by the development of armed military robots in the twenty first century.

Acknowledgments Support from the German Foundation for Peace Research (DSF) and the Joseph Rowntree Charitable Trust for the 2010 workshop in Berlin is gratefully acknowledged. 